American Journal of Infectious Diseases 2 (2): 39-48, 2006

ISSN 1553-6203

(C) 2006 Science Publications

\title{
The Changing Pathology of NeuroAIDS Associated with Drug Abuse in the Era of HAART
}

\author{
${ }^{1}$ Bell Jeanne, E., ${ }^{1}$ Anthony Iain, C. and ${ }^{2}$ Simmonds Peter \\ ${ }^{1}$ Pathology (Neuropathology), University of Edinburgh, Alexander Donald Building \\ Western General Hospital, Edinburgh, EH4 2XU, UK \\ ${ }^{2}$ Centre for Infectious Diseases, University of Edinburgh, Summerhall, Edinburgh, EH9 1QH, UK
}

\begin{abstract}
Compliance with highly active antiretroviral therapy (HAART) arrests HIV induced immune collapse and reduces the prevalence of severe central nervous system (CNS) complications, including HIV associated dementia and encephalitis. However minor cognitive disorders remain common and recent autopsy studies have demonstrated the presence of subtle neuropathological abnormalities in HAART treated individuals, including persistent neuroinflammation and enhanced deposition in the brain of proteins associated with neurodegeneration. The closest comparison group from the pre-HAART era is that comprising presymptomatic HIV infected individuals dying from non HIV related causes. HIV is believed to enter the CNS at or soon after the time of initial infection. Whether this occurs in all HIV infected individuals is unknown. The virus is probably restrained from progressing to a productive CNS infection by systemic and innate immune controls which include surveillance of brain tissue by patrolling CD8 lymphocytes. However HIV is not eliminated from the CNS compartment and is present at low level in the brains of some HAART treated just as in preHAART subjects. Brain viral isolates appear to be neuroadapted and clearly persist long term in the sanctuary of the CNS. This review compares and contrasts data derived from studies of the brain in pre and post HAART cohorts. The implications of increasing longevity in treated individuals who may have low level HIV infection of brain tissue, associated with lymphocytic infiltration and microglial/macrophage activation, are discussed. The exact roles of these cellular reactions in relation to viral suppression are unclear at present. The complexity of this scenario is further heightened when other factors such as illicit drug intake and hepatitis-induced encephalopathy contribute to the clinical outcome. These added insults lead to damaging effects in the brain which may augment those induced by HIV/AIDS. Taken together, these factors suggest that the incidence of HIV-related CNS disorders will rise again in the future.
\end{abstract}

Key words: HAART, brain pathology, drug abuse, neuroinflammation, neurodegeneration

\section{INTRODUCTION}

1996 was a watershed year in the history of the HIV/AIDS epidemic, with the introduction of highly effective antiretroviral therapy (HAART). The simultaneous use of two or more antiviral agents, which disable viral replication in different ways, showed for the first time that treatment could truly arrest the progression of the disease ${ }^{[1,2]}$. Before this date, the terminal phase of immune collapse in infected individuals (AIDS) was frequently complicated by the onset of dementia, associated with underlying brain disease $^{[3]}$. In untreated AIDS the brain was found to be vulnerable not only to opportunistic infections, which might or might not affect other organs, but also to a novel form of encephalitis induced by HIV itself ${ }^{[4-7]}$. Since the introduction of HAART, the incidence of HIV encephalitis (HIVE) and of most central nervous system (CNS) opportunistic conditions, has declined markedly. Not surprisingly, severe cognitive impairment and dementia are also less frequent in HAART treated subjects. However, despite initial optimism, HIV associated neuropsychological abnormalities have not completely disappeared. More subtle derangements of CNS function are not uncommon in HAART treated subjects and contribute significantly to overall morbidity in this group $^{[8]}$

When AIDS first emerged as a novel disease, the dynamics of HIV infection of the brain were studied in the context of the inexorable decline and eventual fatal collapse of the systemic immune system. HIV is capable of attacking both systemic and innate CNS immune systems, through infection respectively of $\mathrm{T}$ helper lymphocytes and of microglia ${ }^{[9,10]}$. In this respect HIV is unique among human viral CNS infections. Experience from the pre HAART era has provided useful data regarding the spectrum of HIV-associated brain disorders at different stages of immune

Corresponding Author: Professor Jeanne E Bell, Pathology (Neuropathology), University of Edinburgh, Alexander Donald Building, Western General Hospital, Edinburgh, EH4 2XU, UK. Tel: + 44131537 1975, Fax: +44 1315371013 
dysfunction $^{[11-13]}$. Compliance with HAART leads to the preservation of partially effective systemic immune mechanisms which appear capable of limiting viral replication in brain tissue ${ }^{[14,15]}$. The resulting precarious equilibrium is reflected in a chronic form of HIV brain disease, which may be clinically occult, or characterised by neuropsychological and neuropathological disorders different from those seen in pre HAART times ${ }^{[8,16]}$. The challenge posed to the neuroAIDS community is to determine how this delicate balance is maintained since any upsets carry the risk of emerging brain disorders in treated individuals. HIVE represents the final breakdown when viral replication outstrips immune control. Current knowledge provides some understanding of these processes but is far from complete.

The stages of NeuroAIDS pathology prior to 1996: Indications that the nervous system is targeted by HIV and vulnerable to opportunistic infections first emerged in the early and mid 1980s, in the novel setting of $\operatorname{AIDS}^{[17]}$. Clinical suspicions of brain involvement were confirmed by neuroimaging and increasingly by autopsy practice, which for obvious reasons generated considerable knowledge about the terminal stages of neuroAIDS pathology ${ }^{[10,12]}$. Although there was considerable overlap in the clinical presentation, neuropathological studies had by 1985 clearly defined HIV infection of the CNS as an entity separate from the various CNS opportunistic conditions ${ }^{[12,18]}$. This latter group included toxoplasmosis, cytomegalovirus (CMV) infection, progressive multifocal leucoencephalopathy (PML) and Epstein Barr virus (EBV) positive CNS lymphomas. HIV was identified in brain tissue by a variety of methods, including immunohistochemistry, in situ hybridisation, electron microscopy and polymerase chain reaction $(\mathrm{PCR})^{[10]}$. A pathognomonic histological feature of productive HIV infection of the CNS is the presence of giant cells ${ }^{[18]}$ and these, with or without immunopositivity for HIV antigens, are the defining features of $\mathrm{HIVE}^{[12]}$.

HIV targets CD4 receptor-positive cells. HIV attaches to host cells by means of an interaction between viral envelope gp120 and a CD4 receptor ${ }^{[19]}$ which leads to unfolding of gp120, allowing penetration of the cell through a chemokine receptor, usually CCR5 or CXCR4 ${ }^{[19]}$. Microglia are the only intrinsic brain cells to possess CD4 receptors, albeit in small numbers. These brain macrophages also bear chemokine receptors, principally CCR5 and are therefore potentially vulnerable to HIV infection once the virus has entered the brain compartment by crossing the blood brain barrier (BBB). Microglia are capable of supporting productive HIV infection and give rise by fusion to the giant cells of $\mathrm{HIVE}^{[20]}$. Brain HIV isolates frequently show evidence of neuroadaptation in that they are highly macrophage tropic and able to infect cells expressing low levels of CD4 and CCR5 ${ }^{[21,22]}$. Occult and restricted infection of other brain cells, notably astrocytes, is also believed to occur ${ }^{[23,24]}$. The mode of viral entry to these cells is unknown since they do not possess CD4 receptors. However, chemokine receptors are widespread in the CNS and HIV DNA has been identified in other cell types, including neurons ${ }^{25-}$ 27]. Infection may therefore occur through a CD4independent route in these cell types, as documented in vitro $^{[28-30]}$. Whether DNA is integrated in these cells in vivo is not known.

Productive HIV infection in the brain induces an inflammatory reaction characterised by activated microglia, both HIV infected and uninfected, together with macrophages and lymphocytes, which are predominately of CD8 phenotype. HIV associated inflammatory cells and giant cells are often concentrated in the perivascular spaces around small blood vessels, particularly in the deep white matter and in the basal ganglia. The cerebral cortical grey matter, the brain stem and the cerebellum may all display evidence of HIVE and productive HIV infection of the spinal cord (HIV myelitis) is also well described ${ }^{[31,32]}$. Neuronal loss has been reported in AIDS and this, together with synaptic and dendritic loss, likely contributes to the cognitive dysfunction of late stage disease although there is no exact correlation between the degree of dementia and the total amount of neuronal $\operatorname{loss}^{[33,34]}$.

Examination of any series of HIVE cases shows that the severity of the disorder varies considerably, a phenomenon which has been rather neglected ${ }^{[10,12]}$. The degree of inflammatory response in HIVE is not uniform and cases may be found in which characteristic giant cells are present in otherwise apparently normal brain tissue. In other cases the inflammation is widespread, conspicuous and accompanied by considerable tissue damage, particularly in white matter which may be extensively demyelinated, with accompanying axonal damage, yet with only a few HIV-immunopositive microglia in occasional microglial nodules. Although the early literature distinguished more inflammatory encephalitic cases (HIV encephalitis) from those with less inflammation and more in the way of white matter pallor and damage (HIV leucoencephalopathy ${ }^{[35]}$, this distinction has not persisted and no universal consensus emerged for separating cases of florid HIVE from those with early or very localised evidence of productive infection. This variability, together with a tendency by researchers to assess the effects of the disorder in subjects in whom HIVE and opportunistic infections coexisted as well as in those with pure HIVE, may explain in part the incomplete concordance between dementia and HIVE. The term HIV encephalopathy has sometimes been 
used synonymously with HIVE but may be more useful in a clinical setting rather than as a neuropathological diagnosis. The pathogenesis of HIV associated dementia (HAD) is usually linked to neuronal loss and damage induced most probably by neurotoxic molecules released from activated and/or infected microglia and macrophages ${ }^{[36,37]}$. Other possible pathogenetic factors include free radicals, excitotoxic neurotransmitters, nitric oxide and chemokines, as well as viral proteins themselves, notably Tat.

HIV enters the brain compartment across the BBB, probably within infected cells of the macrophage lineage ${ }^{[37]}$. Blood derived monocytes migrate into the brain compartment under normal conditions, thereby contributing to the population of perivascular microglia which occupy the specialised microenvironment surrounding small blood vessels in the brain parenchyma $^{[38]}$. Activation of CD14+ and CD16+ monocytes outside the CNS promotes their penetration of the $\mathrm{BBB}^{[39]}$. If these cells are also HIV infected, this transmigration into the CNS may constitute the earliest step in HIV neuroinvasion, thereby inducing the lymphocytic reaction observed in the brains of many presymptomatic HIV infected individuals ${ }^{[13,40]}$. Since these individuals have died of causes unrelated to HIV and apparently before the onset of AIDS, it is unlikely that AIDS related HIV encephalitis or CNS opportunistic conditions are present. Other subtle cellular reactions occur in the brain in pre-AIDS including microglial activation and astrocytosis ${ }^{[13,41]}$. HIV can be detected by PCR at low level within brain tissue in pre-AIDS ${ }^{[40,42]}$. Examination of the cerebrospinal fluid (CSF) also suggests that infection of the CNS compartment occurs in presymptomatic individuals since both virus and antibody can be detected in CSF before the onset of AIDS ${ }^{[43-45]}$. Caution has been expressed about assuming that the CSF always reflects concurrent events in the brain compartment ${ }^{[46]}$. Examination of one recently infected individual, in whom the amount of virus detected within brain tissue exceeded that found in plasma, provided powerful evidence to support direct infection of the CNS at an early stage $^{[47]}$. Occasional subjects develop clinical symptoms relating to the CNS immediately after becoming infected. The onset of meningitis and/or encephalitis at the time of seroconversion does suggest that early neuroinvasion occurs. Very similar findings in simian and feline immunodeficiency virus (SIV and FIV) infection also provide support for the concept of early CNS HIV infection ${ }^{[48,49]}$.

Brain HIV isolates nearly always retain a macrophage-tropic phenotype even in advanced AIDS $^{[21]}$. The viral characteristics of untreated early brain infection have been explored recently by limiting dilution PCR quantitation and V3 genotyping in matched brain and lymphoid tissues from presymptomatic HIV infected individuals ${ }^{[42]}$. These studies confirm the presence of low level brain viral infection in some but not all cases. As observed in AIDS cases, brain variants are frequently genetically distinct from those found in lymphoid tissue in the same individual, providing further evidence that brain infection is distinct and separate from the parallel process in the systemic compartment even in the earlier stages of infection. These studies also revealed a direct relationship between the brain viral burden and the degree of CD8 infiltration in the CNS, suggesting that the latter may be significant in responding to HIV and in limiting its replication in this site.

It remains unclear whether HIV neuroinvasion occurs only in some individuals or whether it occurs in all and is subsequently eradicated or effectively controlled in a proportion, who are then protected from the later onset of HIVE. It seems plausible that other factors may play a part in determining events, including the level of CNS immune surveillance and CD8 trafficking as well as the presence of other brain insults affecting the integrity of the BBB. It is also likely that HIV penetration of the BBB occurs repeatedly through the course of the illness and that the emergence of neurovirulent species in the brain results from interaction and mosaicism between early and late entrants $^{[50]}$. Although aspects of HIV infection of the brain are not well understood to this day, it seems that HAART induced suppression of HIV replication within the systemic compartment has been most effective in reducing the CNS complications. This breakthrough followed on early treatment with the reverse transcriptase inhibitor, Zidovudine, which was somewhat effective in treating HAD in the short term but ultimately unsuccessful because of failure to arrest the progress of immune collapse ${ }^{[51]}$. The emergence by mutation of drug resistant HIV variants has always posed problems for systemic therapy but the extent to which this happens in the CNS is poorly understood, not least because the penetration of therapeutic drugs through the $\mathrm{BBB}$ is variable ${ }^{[52-54]}$.

The HAART treated brain: Treatment with HAART has had a dramatic impact on the mortality of HIV infected individuals who are now surviving long term. The reduction of plasma viral load and the partial reversal of immune decline allows the prolongation of the presymptomatic phase of the infection ${ }^{[14,15]}$. However the early hopes for achieving viral eradication proved false and the CNS is known to be one of a number of organs in which persistent virus can be sheltered long term ${ }^{[55]}$. The inhibitors of protease and of reverse transcriptase which make up the HAART cocktail are not particularly effective in penetrating the BBB (apart from Zidovudine) and achieve their impact on the prevalence of CNS infection mainly as a result of 
an improvement in systemic immune function ${ }^{[56,57]}$. Despite beneficial effects overall, it has become clear that many HAART treated individuals do suffer minor cognitive impairment ${ }^{[8,14]}$. Depression and other mood disorders are also more common than in uninfected individuals. Some patients who have already developed HAD do improve following the commencement of HAART but others do not and it may be that in these cases neural damage is already too far advanced to be effectively reversed [6]. Some recent studies have suggested a shift towards a neocortical form of cognitive impairment rather than the subcortical dementia which was characteristic of the preHAART $\mathrm{era}^{[58]}$.

Although the previous pattern of AIDS related illnesses has been considerably modified by HAART, the overall prevalence of HIV associated morbidity is rising because of the increasing numbers of treated individuals ${ }^{[59]}$. HAART treated individuals may die of other, comorbid conditions such as hepatitis and drug related conditions. Fewer autopsies are now undertaken and knowledge of the neuropathology in these subjects is far from complete ${ }^{[5,7,60,61]}$. Despite the apparent reduction of HAD, HIVE remains surprisingly common and has been described in up to $25 \%$ of autopsy cases in the post HAART era ${ }^{[7]}$. It is of course possible that such cases may not have been optimally HAART compliant and are not representative of surviving subjects. PML, resulting from uncontrolled replication of JC virus and Epstein Barr virus related primary CNS lymphoma are also reported in HAART treated individuals. However overall the incidence of opportunistic conditions has been reduced. Burnt out forms of HIVE and other CNS infections have been described ${ }^{[6,60]}$ although these conditions were also recognised in pre HAART individuals. Quite often the brain appears unremarkable on routine examination in well treated subjects ${ }^{[62]}$. However more detailed investigation confirms an upregulation in CD8 lymphocytes, both in the perivascular space and in the meninges. Occasional dramatic cases have been described in which the brain displays a very severe, acute demyelinating condition associated with massive, non neoplastic lymphoid infiltrate and linked with immune reconstitution in the context of HAART ${ }^{[6,63]}$. Mild astrocytosis is also seen in the brain of HAART treated individuals to a level comparable with presymptomatic and non HIVE AIDS cases. The most unexpected finding in HAART treated cases is the presence of a high level of microglial activation, as measured by CD68 (Fig 1) and MHCII positivity which is comparable with the levels seen in HIVE. The brain proviral load appears to be low in HAART compliant cases, in keeping with the reduction in HIV encephalitis.

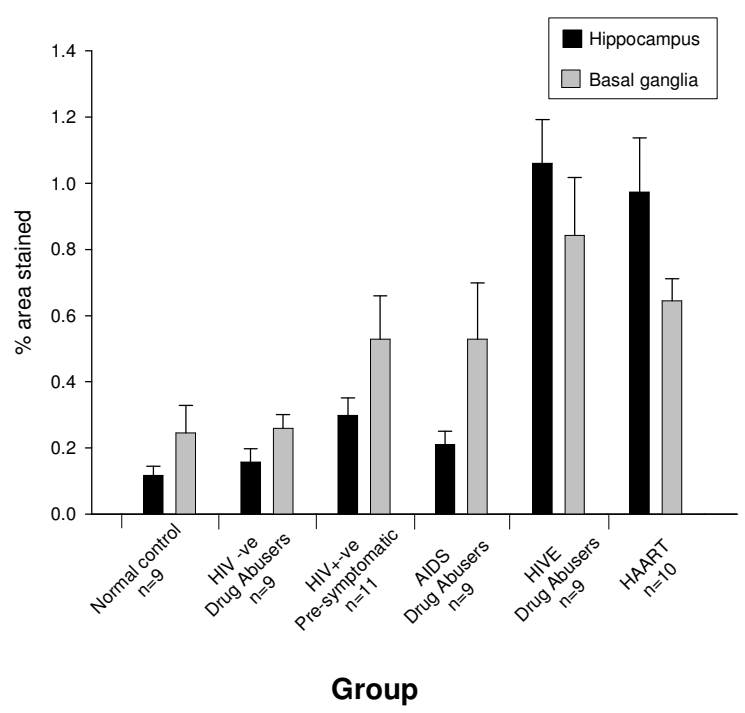

Fig. 1: Bar chart showing CD68 positive microglial quantitation in various groups of HIV infected individuals. Results for the hippocampus and basal ganglia are shown. With this marker protein of activation, changes in the HAART treated group are similar to those seen in HIVE

Studies from several different centres have suggested that the brains of HAART treated individuals display the premature appearance of insoluble proteins associated with neurodegeneration. These proteins include hyperphosphorylated $\mathrm{Tau}^{[64]}$, ubiquitin ${ }^{[65]}$ and $\beta_{\text {amyloid }}^{[66]}$. A rise in hyperphosphorylated Tau in the CSF of HAART treated subjects has also been reported [67]. HAART itself is known to be toxic for mitochondria and the effect of this may be amplified by other agents such as illicit drug intake ${ }^{[68,69]}$. Concern has been expressed about the effects of low level viral burden and of chronic inflammation on the long term outlook for individuals who are surviving with treated HIV infection. In the presence of changes such as these in brains of HAART treated individuals it may not be surprising that dementia is now reported to be more prevalent in older HIV positive individuals, compared with age matched controls $^{[70]}$.

The role of drugs of abuse: Drugs of abuse penetrate the CNS with ease where they exert their desired mood changing effects. Because these drugs can cause damage to the BBB and to neuronal systems, as well as having a general immunosuppressive effect, it has long been postulated that the combined effects of drug abuse and HIV/AIDS may be particularly damaging for the CNS. 
The groups of drugs which are open to abuse include stimulants (including cocaine, amphetamines, cannabis), analgesics and narcotics (heroin, methadone and other opiates), hypnotics (barbiturates and diazepines) and antidepressants. Most drug users have a favoured drug of choice but mixed drug intake is common and usually compounded by alcohol intake and addiction to nicotine. This complicates the study of the effects of human drug abuse and the most that can be said is that particular illicit drugs tend to predominate in different communities and countries and at different times depending on availability. Heroin and other opiate misuse has been common in UK and mainland Europe and cocaine use is gaining in popularity.

Drugs self administered by injection carry additional risks of transmission of blood borne viruses, including HIV and hepatitis B and C and of other infective agents causing septicaemia and endocarditis $^{[71,72]}$. The risk of infection is heightened by the immune suppressive effects of some drugs ${ }^{[73,74]}$. Hepatitis may cause a metabolic encephalopathy, characterised by astrocyte dysfunction and disturbances in glutamate buffering particularly in the basal ganglia $^{[75]}$. Occasional drug use may have dangerous side effects such as hyperthermia, but it is sustained and habituated use which is most damaging ${ }^{[76,77]}$. Opiates cause respiratory depression which is potentiated by excess alcohol use. Within the CNS, drugs of abuse affect the circulation, causing cerebral oedema and hypoxia, vasculitis and acute and chronic breakdown of the BBB. Haemorrhagic or ischaemic strokes are not uncommon in drug abusers including young subjects, leading to damage in both white and grey matter ${ }^{[68,78,79]}$.

Both neurons and glial cells have surface receptors which readily interact with all classes of drugs ${ }^{[80,81]}$. Opiates and cocaine achieve their desired effect by affecting dopamine release or uptake ${ }^{[68,82]}$. Dopaminergic neurons may be at risk when exposed to amphetamines and opiates ${ }^{[83]}$. Subtle neuronal damage and/or intermittent hypoxic damage may be the cause of microglial activation which is also observed in the brains of regular drug abusers ${ }^{[41,84]}$. These activated cells are able to release cytokines, particularly tumour necrosis factor alpha, which are pro-inflammatory and potentially neurotoxic ${ }^{[85]}$. An excess of hyperphosphorylated Tau has been reported in the brains of young opiate users, possibly reflecting recurrent hypoxic episodes associated with their habit $^{[86]}$.

Many of these effects overlap with those induced in the CNS by HIV/AIDS and may be additive. Intravenous drug abusers may acquire HIV infection at a young age. Whether drug users then progress to AIDS more rapidly remains unclear. There is some evidence that dementia and cognitive impairment may be more common in HIV infected drug abusers than in other risk groups $^{[87]}$. Increased dopamine levels have been postulated as a mediator of HIV associated neurological and cognitive deficits ${ }^{[88]}$. Advancing HIV/AIDS may also expose underlying premorbid personality disorders in drug users.

We and others have reported that, prior to the advent of HAART, HIVE occurred more frequently in drug users with AIDS than in other risk groups ${ }^{[89,90]}$ but this has not been universal experience ${ }^{[35,91,92]}$. For drug users enrolled in HAART regimes, the major cause of death is now hepatitis, which may be difficult to treat in the context of HIV co-infection. The prevalence of HIVE has also declined, at least in part because most deaths of HIV infected drug abusers now occur before the onset of symptomatic AIDS and are usually not related to their HIV infection. Despite the absence of productive HIV infection, examination of their brains reveals microglial activation to a high degree, comparable with the levels present in AIDS and HIVE (pre HAART). Hyperphosphorylated Tau is also present in excess in the brains of HAART-treated drug users, suggesting ongoing neuronal damage particularly in the medial temporal lobe. Both Tau positive neurofibrillary tangles and neuritic threads are observed. These neuropathological abnormalities are currently below the clinical threshold in that no cognitive deficit had been observed in life but do not augur well for the longer term in chronic HIV infection. Emerging evidence suggests that increased $\beta$ amyloid deposition occurs in the brains of HIV infected individuals, compared with age matched controls and it is postulated that this may be the consequence of HIV Tat induced suppression of neprilysin, an enzyme which promotes the degradation of $\beta_{\text {amyloid }}{ }^{[93]}$. The observation of increased prevalence of neurocognitive decline in older treated individuals is in keeping with these predictions.

\section{CONCLUSION}

Chronic HIV infection of the brain is a new disease which requires further study directed not only to determining the basis of current morbidity, including minor cognitive and mood disorders, but also the likely effects of persistent neuroinflammation, particularly with advancing age. Neuroinflammation in the form of microglial/macrophage activation has been implicated as a major pathogenetic factor in the onset of AIDS dementia and is common in other dementing illnesses such as Alzheimer's disease and neurosyphilis.

Innate CNS immune reactions, including microglial responses, are implicated in maintaining the uneasy equilibrium between HIV replication in the CNS on the one hand and systemically supported immune surveillance and influx on the other. 
Observation suggests that CD8 lymphocyte entry to the brain in the context of HAART requires careful titration; too few and viral escape may ensue whereas too many may expose brain tissue to the risk of injury as described in the immune reconstitution syndrome. The fact that microglia themselves are the target of infection and able to produce both neuroprotective and proinflammatory cytokines further complicates the fine balance required to remain symptom free ${ }^{[94]}$. It remains to be seen whether entirely novel scenarios might emerge in the HAART treated CNS in the future, given the state of chronic partial immunosuppression. For instance hepatitis $C$ may prove to be neurotropic ${ }^{[95,96]}$ and TT virus (TTV) has also attracted attention as a possible hazard for the $\mathrm{CNS}^{[97]}$. Only time will tell.

\section{ACKNOWLEDGEMENTS}

HIV related research in Edinburgh has been supported long term by the UK Medical Research Council (G9708080) and latterly by US National Institute on Drug Abuse (IROI DA13117 \& IROI DA13840). We gratefully acknowledge the support of our clinical colleagues, the scientists and graduate students who have worked in our research group over the years and not least the families affected by HIV/AIDS in Edinburgh. Mrs Frances Carnie has provided expert technical assistance and Ms Angela Penman prepared the manuscript.

\section{REFERENCES}

1. Hogg, R.S., M.V. O'Shaughnessy, N. Gataric and B. Yip, K. Craib, M.T. Schechter, J.S.G. Montaner, 1997. Decline in deaths from AIDS due to new antiretrovirals. Lancet, 349:1294.

2. McArthur J.C., D.R. Hoover, H. Bacellar, E.N. Miller, B. Cohen, J.T. Becker, N.M. Graham, J.H. McArthur, O.A. Selnes and L.P. Jacobson, 1993. Dementia in AIDS patients: incidence and risk factors. Multicenter AIDS cohort study. Neurology, 43: 2245-2252.

3. Gehrmann, J., P. Kleihues, 1994. Neuropathology of central nervous system human immunodeficiency virus infection. Curr. Diag. Pathol., 1:121.

4. Langford, T.D., S.L. Letendre, G.J. Larrea and E. Masliah, 2003. Changing patterns in the neuropathogenesis of HIV during the HAART era. Brain Pathol., 13: 195-210.

5. Morgello, S., R. Mahboob, T. Yakoushina, S. Khan and K. Hague, 2002. Autopsy findings in human immunodeficiency virus-infected population over 2 decades: influences of gender, ethnicity, risk factors and time. Arch. Pathol. Lab. Med., 126: 182-190.
6. Gray, F., F. Chretien, A.V. Vallat-Decouvelaere and F. Scaravilli, 2003. The changing pattern of HIV neuropathology in the HAART era. J. Neuropathol. Expl. Neurol., 62: 429-440.

7. Masliah, E., R.M. DeTeresa, M. Mallory and L. Hansen, 2000. Changes in pathological findings at autopsy in AIDS cases for the last 15 years. AIDS, 14: 69-74.

8. Sacktor, N., M.P. McDermott, K. Marder, G. Schifitto, O.A. Selnes, J.C. McArthur, T. Stern, S. Albert, D. Palumbo, K. Kieburtz, J.A. De Marcaida, B. Cohen, L.G. Epstein, 2002. HIVassociated cognitive impairment before and after the advent of combination therapy. J. NeuroVirol., 8: 136-142.

9. Kure, K., K.M. Weidenheim, W.D. Lyman and D.W. Dickson, 1990. Morphology and distribution of HIV-1 gp41-positive microglia in subacute AIDS encephalitis. Acta Neuropatholog., 80: 393400.

10. Budka, H., G. Costanzi, S. Cristina, A. Lechi, C. Parravicini, R. Trabattoni and L. Vago, 1987. Brain pathology induced by infection with the human immunodeficiency virus (HIV): a histological, immunocytochemical and electron microscopical study of 100 cases. Acta Neuropatholog., 75: 185198.

11. Budka, H., C. A. Wiley, P. Kleihues, J. Artigas, A. K. Asbury, E.S. Cho, D.R. Cornblath, M.C. Dal Canto, U. De Girolami, D.W. Dickson, L.G. Epstein, M.M. Esiri, F. Giangaspero, G. Gosztonyi, F. Gray, J. W. Griffin, D. Henin, Y. Iwasaki, R.S. Janssen, R.T. Johnson, P.L. Lantos, W.D. Lyman, J.C. McArthur, K. Nagashima, N. Peress, C.K. Petito, R.W. Price, R.H. Rhodes, M. Rosenblum, G. Said, F. Scaravilli, L.R. Sharer and H.V. Vinters, 1991. HIV-associated disease of the nervous system: Review of nomenclature and proposal for neuropathology-based terminology. Brain Pathol., 1: 143-152.

12. Budka, H., 1991. Neuropathology of human immunodeficiency virus infection. Brain Pathol., 1: 163-175.

13. Gray, F., F. Scaravilli, I. P. Everall, F. Chretien, D. Boche, H. Adle-Biassette, L. Wingertsmann, M. Durigon, B. Hurtrel, F. Chiodi, J.E. Bell and P.L. Lantos, 1996. Neuropathology of early HIV-1 infection. Brain Pathol., 6: 1-15.

14. McArthur, J.C., N.J. Haughey, S. Gartner, K. Conant, C. Pardo, A. Nath and N. Sacktor, 2003. Human immunodefiniency virus-associated dementia: An evolving disease. J. NeuroVirol., 9: 205-221.

15. Swindells, S., J. Zheng and H.E. Gendelman, 1999. HIV-associated dementia: New insights into disease pathogenesis and therapeutic interventions. AIDS Patient Care and STDs, 13: 153-163. 
16. Bell, J.E., 2004. An update on the neuropathology of HIV in the HAART era. Histopathology, 45: 549-559.

17. Welch, K., W. Finkbeiner, C.E. Alpers, W. Blumenfeld, R.L. Davis, E.A. Smuckler and J.H. Beckstead, 1984. Autopsy findings in the acquired immune deficiency syndrome. JAMA, 252: 11521159.

18. Sharer, L.R., E.S. Cho and L.G. Epstein, 1985. Multinucleated giant cells and HTLV-III in AIDS encephalopathy. Human Pathol., 16: 760.

19. Clapham, P.R. and A. McKnight, 2001. HIV-1 receptors and cell tropism. Br. Med. Bull., 58: 4359.

20. Dickson, D.W., 1986. Multinucleated giant cells in acquired immunodeficiency syndrome encephalopathy. Origin from endogenous microglia? Arch. Patholol. Lab. Med., 110: 967968.

21. Peters, P.J., J. Bhattacharya, S. Hibbitts, M.T. Dittmar, G. Simmons, J. Bell, P. Simmonds and P.R. Clapham, 2004. Biological analysis of human immunodeficiency virus type 1 R5 envelopes amplified from brain and lymph node tissues of AIDS patients with neuropathology reveals two distinct tropism phenotypes and identifies envelopes in the brain that confer an enhanced tropism and fusigenicity for macrophages. J. Virol., 78: 6915-6926.

22. Gorry, P.R., J. Taylor, G.H. Holm, A. Mehle, T. Morgan, M. Cayabyab, M. Farzan, H. Wang, J.E. Bell, K. Kuntsman, J.P. Moore, S.M. Wolinsky and D. Gabuzda, 2002. Increased CCR5 affinity and reduced CCR5/CD4 dependence of a neurovirulent primary human immunodeficiency virus type 1 isolate. J. Virol., 76: 6277-6292.

23. Brack-Werner, R., 1999. Astrocytes: HIV cellular reservoirs and important participants in neuropathogenesis. AIDS, 13: 1-22.

24. Takahashi, K., S.L. Wesselingh, D.E. Griffin, J.C. McArthur, R.T. Johnson, J.D. Glass, 1996. Localization of HIV-1 in human brain using polymerase chain reaction/in situ hybridization and immunocytochemistry. Ann. Neurol., 39: 705-711.

25. Bagasra, O., E. Lavi, L. Bobroski, K. Khalili, J.P. Pestaner, R. Tawadros and R.J. Pomerantz, 1996. Cellular reservoirs of HIV-1 in the central nervous system of infected individuals: identification by the combination of in situ polymerase chain reaction and immunohistochemistry. AIDS, 10: 573-585.

26. Torres-Munoz, J., P. Stockton, N. Tacoronte, B. Roberts, R.R. Maronpot and C.K. Petito, 2001. Detection of HIV-1 gene sequences in hippocampal neurons isolated from postmortem AIDS brains by laser capture microdissection. J. Neuropathol. Expl. Neurol., 60: 885-892.
27. Trillo-Pazos, G., A. Diamanturos, L. Rislove, T. Menza, W. Chao, P. Belem, S. Sadiq, S. Morgello, L.R. Sharer and D.J. Volsky, 2003. Detection of HIV-1 DNA in microglia/macrophages, astrocytes and neurons isolated from brain tissue with HIV-1 encephalitis by laser capture microdissection. Brain Pathol., 13: 144-154.

28. Lopez-Herrera, A., Y. Liu, M.T. Rugeles and J.J. He, 2005. HIV-1 interaction with human mannose receptor (hMR) induces production of matrix metalloproteinase 2 (MMP-2) through hMRmediated intracellular signaling in astrocytes. Biochemist. Biophys. Acta, 1741: 55-64.

29. Gorry, P.R., C. Ong, J. Thorpe, S. Bannwarth, K. A. Thompson, A. Gatignol, S.L. Vesselingh and D.F. Purcell, 2003. Astrocyte infection by HIV-1: mechanisms of restricted virus replication and role in the pathogenesis of HIV-1-associated dementia. Curr. HIV Res., 1:463-473.

30. Willey, S J., J.D. Reeves, R. Hudson, K. Miyake, N. Dejucq, D. Schols, E. De Clercq, J. Bell, A. McKnight, P.R. Clapham, 2003. Identification of a subset of human immunodeficiency virus type 1 (HIV-1), HIV-2 and simian immunodeficiency virus strains able to exploit an alternative coreceptor on untransformed human brain and lymphoid cells. J. Virol., 77: 6138-6152.

31. Bell, J.E., R.P. Brettle, A. Chiswick, P. Simmonds, 1998. HIV encephalitis, proviral load and dementia in drug users and homosexuals with AIDS. Effect of neocortical involvement. Brain, 121: 2043-2052.

32. Shepherd, E.J., R.P. Brettle, P.P. Liberski, A. Aguzzi, J.W. Ironside, P. Simmonds and J.E. Bell, 1999. Spinal cord pathology and viral burden in homosexuals and drug users with AIDS. Neuropathol. Appl. Neurobiol., 25: 2.

33. Adle-Biassette, H., Y. Levy, M. Colombel, F. Poron, S. Natchev, K. Keohane and F. Gray, 1995. Neuronal apoptosis in HIV infection in adults. Neuropathol. Appl. Neurobiol., 21: 218-227.

34. Everall, I.P., P.J. Luthert and P.L. Lantos, 1993. Neuronal number and volume alterations in the neocortex of infected individuals. J. Neurol., Neurosurg. Psychiat., 56: 481-486.

35. Budka, H., 1989. Human immunodeficiency virus (HIV)-induced disease of the central nervous system: Pathology and implications for pathogenesis. Acta Neuropatholog., 77: 225-236.

36. Glass, J.D., H. Fedor, S.L. Wesselingh and J.C. McArthur, 1995. Immunocytochemical quantition of HIV in the brain: correlations with dementia. Ann. Neurol., 38: 755-762.

37. Anderson, E., W. Zink, H. Xiong and H.E. Gendelman, 2002. HIV-1-associated dementia: A metabolic encephalopathy perpetrated by virusinfected and immune-competent mononuclear phagocytes. J. Acquir. Immune Defic. Syndr., 31: S43-S54. 
38. Kennedy, D.W. and J.L. Abkowitz, 1997. Kinetics of central nervous system microglial and macrophage engraftment: Analysis using a transgenic bone marrow transplantation model. Blood, 90: 986-993.

39. Fischer-Smith, T., S. Croul, A. Adeniyi, K. Rybicka, S. Morgello, K. Khalili and J. Rappaporat, 2004. Macrophage/microglial accumulation and proliferating cell nuclear antigen expression in the central nervous system in human immunodeficiency virus encephalopathy. Am. J. Pathol., 164: 2089-2099.

40. Bell, J.E., A. Busuttil, J.W. Ironside, S. Rebus, Y. K. Donaldson, P. Simmonds and J.F. Peutherer, 1993. HIV and the brain: investigation of viral load and neuropathological changes in pre-AIDS subjects. J. Infect. Dis., 168: 818-824.

41. Tomlinson, G.S., P. Simmonds, A. Busuttil, A. Chiswick and J.E. Bell, 1999. Upregulation of microglia in drug users with and without presymptomatic HIV infection. Neuropathol. Appl. Neurobiol., 25: 369-379.

42. McCrossan, M., M. Marsden, F.W. Carnie, S. Minnis, B. Hansoti, I.C. Anthony, R.P. Brettle, J.E. Bell and P. Simmonds, 2006. An immune control model for viral replication in the CNS during presymptomatic HIV infection. Brain, 129:503516.

43. Ho, D.D., M.G. Sarngadharan, L. Resnick, F. Dimarzoveronese, T.R. Rota and M.S. Hirsch, 1985. Primary human T-lymphotropic virus type III infection. Ann. Intern. Med., 103: 880-883.

44. Resnick, L., J.R. Berger, P. Shapshak and W.W. Tourtellotte, 1988. Early penetration of the bloodbrain-barrier by HIV. Neurol., 38: 9-14.

45. Goudsmit, J., F. de Wolf, D.A. Paul, L.G. Epstein, J.M. Lange, W.J. Krone, H. Speelman, E.C. Wolters, J. Van der Noordaa and J.M. Oleske, 1986. Expression of human immunodeficiency virus antigen (HIV-Ag) in serum and cerebrospinal fluid during acute and chronic infection. Lancet, 2:177-180.

46. Price, R.W. and S. Staprano, 1997. Measuring the "viral load" in cerebrospinal fluid in human immunodeficiency virus infection: window into brain infection? Ann. Neurol., 42: 675-678.

47. Davis, L.E., B.L. Hjelle, V.E. Miller, D.L. Palmer, A.L. Llewellyn, T.L. Merlin, S.A. Young, R.G. Mills, W. Wachsman and C.A. Wiley, 1992. Early viral brain invasion in iatrogenic human immunodeficiency virus infection. Neurology, 42:1736-1739.

48. Chakrabarti, L., M. Hyrtel, M.A. Maire, R. Vazeux, D. Dormont, L. Montagnier and B. Hurtrel, 1991. Early viral replication in the brain of SIV-infected rhesus monkeys. Am. J. Pathol., 139: 1273-1280.
49. Hurtrel, M., J.P. Ganiere, J.F. Guelfi, L. Chakrabarti, M.A. Maire, F. Gray, L. Montagnier and B. Hurtrel, 1992. Comparison of early and late feline immunodeficiency virus encephalopathies. AIDS, 6: 399-406.

50. Hughes, E.S., J.E. Bell and P. Simmonds, 1997. Investigation of the dynamics of the spread of human immunodeficiency virus to brain and other tissues by evolutionary analysis of sequences from the p17gag and env genes. J. Virol., 71:1272-1280.

51. Portegies, P., R.H. Enting, P.R. Algra, M.M. Derix, J.M. Lange and J. Goudsmit, 1993. Presentation and course of AIDS dementia complex: 10 years follow up in Amsterdam. AIDS, 7:669-675.

52. Kandanearatchi, A., B. Williams and I.P. Everall, 2003. Assessing the efficacy of highly active antiretroviral therapy in the brain. Brain Pathol., 13: 104-110.

53. Smit, T.K., B.J. Brew, W. Tourtellotte, S. Morgello, B.B. Gelman and N.K. Saksena, 2004. Independent evolution of human immunodeficiency virus (HIV) drug resistance mutations in diverse areas of the brain in HIVinfected patients, with and without dementia, on antiretroviral treatment. J. Virol., 78: 10133-10148.

54. Bestetti, A., S. Presi, C. Pierotti, S. Bossolasco, S. Sala, S. Racca, P. Carrera, A. Lazzarin and P. Cinque, 2004. Long-term virological effect of highly active antiretroviral therapy on cerebrospinal fluid and relationship with genotypic resistance. J. NeuroVirol., 10: 52-57.

55. Lambotte, O., K. Deiva and M. Tardieu, 2003. HIV-1 persistence, viral reservoir and the central nervous system in the HAART era. Brain Pathol., 13:95-103.

56. Albright, A.V., S. S. Soldan, F. Gonzalez-Scarano, 2003. Pathogenesis of human immunodeficiency virus-induced neurological disease. J. NeuroVirol., 9: 222-227.

57. Enting, R.H., R.M.W. Hoetelmans, J.M. Lange, D.M. Burger, J.H. Beijnen and P. Portegies, 1998. Antiretroviral drugs and the central nervous system. AIDS, 12: 1941-1955.

58. Brew, B.J., 2004. Evidence for a change in AIDS dementia complex in the era of highly active antiretroviral therapy and the possibility of new forms of AIDS dementia complex. AIDS, 18: S75S78.

59. Neuenburg, J.K., H.R. Brodt, B.G. Herndier, M. Bickel, P. Bacchetti, R.W. Price, R.M. Grant and W. Schlote, 2002. HIV-related neuropathology, 1985 to 1999: rising prevalence of HIV encephalopathy in the era of highly active antiretroviral therapy. J. Acquir. Immune. Defic. Syndr., 31: 171-177. 
60. Gray, F. and K. Keohane, 2003. The neuropathology of HIV infection in the era of highly active antiretroviral therapy (HAART). Brain Pathol., 13: 79-83.

61. Jellinger, K., U. Setinek, M. Drlicek, G. Bohm, A. Steurer and F. Lintner, 2000. Neuropathology and general autopsy findings in AIDS during the last 15 years. Acta Neuropatholog. (Berl), 100: 213-220.

62. Anthony, I.C., S.N. Ramage, F.W. Carnie, P. Simmonds and J. Bell, 2005. Influence of HAART of HIV related CNS disease and neuroinflammation. J. Neuropathol. Expl. Neurol., 64: 529-536.

63. Langford, T.D., S.L. Letendre, D.T. Marcotte, R.J. Ellis, J.A. McCutchan, I. Grant, M. Mallory, L. Hansen, S. Archibald, T. Jernigan, E. Masliah and H. Group, 2002. Severe, demyelinating leukoencephalopathy in AIDS patients on antiretroviral therapy. AIDS, 16: 1019-1029.

64. Anthony, I.C., S.N. Ramage, F.W. Carnie and J.E. Bell, 2006. Accelerated tau deposition in the brains of individuals infected with HIV-1 before and after the advent of HAART. Acta Neuropatholog., (Berl), EPub ahead of print.

65. Gelman, B.B. and K. Schuenke, 2004. Brain aging in acquired immunodeficiency syndrome: increased ubiquitin-protein conjugate is correlated with decreased synaptic protein but not amyloid plaque accumulation. J. NeuroVirol., 10: 98-108.

66. Green, D.A., E. Masliah, H.V. Vinters, P. Beizai, D.J. Moore and C.L. Achim, 2005. Brain deposition of beta-amyloid is a common pathologic feature in HIV positive patients. AIDS, 19: 407411.

67. Brew, B.J., L. Pemberton, K. Blennow, A. Wallin and L. Hagberg, 2005. CSF amyloid beta42 and tau levels correlate with AIDS dementia complex. Neurology, 65: 1490-1492.

68. Karch, S.B., 2002. The Pathology of Drug Abuse. Boca Raton, Florida: CRC Press, pp: 1.

69. Bell, J.E. and F. Gray, 2004. Brain Pathology in HIV-1 Infected Drug Abusers. Gendelman H. E., I. P. Everall, I. Grant, S. A. Lipton, S. Swindells, editors. Oxford: Oxford City Press.

70. Valcour, V., C. Shikuma, B. Shiramizu, M. Watters, P. Poff, O. Selnes, P. Holck, J. Grove and N. Sacktor, 2004. Higher frequency of dementia in older HIV-1 individuals: The Hawaii Aging with HIV-1 Cohort. Neurology, 63: 822-827.

71. Kresina, T.F., J. Khalsa, H. Cesari and H. Francis, 2005. Hepatitis $\mathrm{C}$ virus infection and substance abuse: Medical management and developing models of integrated care--an introduction. Clin. Infect. Dis., 40 (Suppl. 5): S259-262.
72. Khalsa, J.H., T. Kresina, K. Sherman and F. Vocci, 2005. Medical management of HIV-hepatitis C virus coinfection in injection drug users. Clin. Infect. Dis., 41 (Suppl. 1): S1-6.

73. Fiala, M., X.H. Gan, L. Zhang, S.D. House, T. Newton, M.C. Graves, P. Shapshak, M. Stins, K.S. Kim, M.H. Witte and S.L. Chang, 1998. Cocaine enhances monocyte migration across the bloodbrain barrier. Cocaine's connection to AIDS dementia and vasculitis? Adv. Expl. Med. Biol., 437: 199-205.

74. Carr, D.J. and M. Serou, 1995. Exogenous and endogenous opioids as biological response modifiers. Immunopharmacology, 31: 59-71.

75. Butterworth, R.F., 2003. Hepatic encephalopathy. Alcohol Res. Health, 27: 240-246.

76. Nath, A., K.F. Hauser, V. Wojna, R.M. Booze, W. Maragos, M. Prendergast, W.A. Cass and J.T. Turchan, 2002. Molecular basis for interactions of $\mathrm{HIV}$ and drugs of abuse. J. Acquir. Immune. Defic. Syndr., 31: S62-S69.

77. Peterson, P.K., T.W. Molitor and C.C. Chao, 1998. The opioid-cytokine connection. J. Neuroimmunol., 83: 63-69.

78. Buttner, A., G. Mall, R. Penning and S. Weis, 2000. The neuropathology of heroin abuse. Forensic Sci. Intl., 113: 435-442.

79. Levine, S.R., J.C. Brust, N. Futrell, K.L. Ho, D. Blake, C.H. Millikan, L.M. Brass, P. Fayad, L.R. Schultz, J.F. Selwa and K. Welch, 1990. Cerebrovascular complications of the use of the "crack" form of alkaloidal cocaine. New Engl. J. Med., 323: 699-704.

80. Calligaro, D.O. and M.E. Eldefrawi, 1987. Central and peripheral cocaine receptors. J. Pharmacol. Expl. Therap., 243: 61-68.

81. Connor, M. and M.D. Christie, 1999. Opioid receptor signalling mechanisms. Clin. Expl. Pharmacol. Physiol., 26: 493-499.

82. Basso, M.R. and R.A. Bornstein, 2000. Neurobehavioural consequences of substance abuse and HIV infection. Psychopharmacology, 14: 228-237.

83. Ernst, T., L. Chang, M. Leonido-Yee and O. Speck, 2000. Evidence for long-term neurotoxicity associated with methamphetamine abuse: A1M MRS study. Neurology, 54: 1344-1349.

84. Gosztonyi, G., V. Schmidt, R. Nickel, M.A. Rothschild, S. Camacho, G. Siegel, E. Zill, G. Pauli and V. Schneider, 1993. Neuropathologic analysis of postmortal brain samples of HIVseropositive and seronegative IV drug addicts. Forensic Sci. Intl., 62: 101-105.

85. Nath, A. and J.D. Geiger, 1998. Neurobiological aspects of HIV infections: neurotoxic mechanisms. Prog. Neurobiol., 54: 19-33. 
86. Ramage, S.N., I.C. Anthony, F.W. Carnie, A. Busuttil, R. Robertson and J. Bell, 2005. Hyperphosphorylated tau and amyloid precursor protein deposition is increased in the brains of young drug abusers. Neuropathol. Appl. Neurobiol., 31: 439-448.

87. Chiesi, A., A.C. Seeber, L.G. Dally, M. Floridia, G. Rezza and S. Vella, 1996. AIDS dementia complex in the Italian National AIDS Registry: temporal trends (1987-93) and differential incidence according to mode of transmission of HIV-1 infection. J. Neurolog. Sci., 144:107-113.

88. Koutsilieri, E., S. Sopper, C. Scheller, V. ter Meulen and P. Riederer, 2002. Involvement of dopamine in the progression of AIDS Dementia Complex. J. Neural Transmission, 109: 399-410.

89. Bell, J.E., Y.K. Donaldson, S. Lowrie, C.A. McKenzie, R.A. Elton, A. Chiswick, R.P. Brettle, J.W. Ironside and P. Simmonds, 1996. Influence of risk group and zidovudine therapy on the development of HIV encephalitis and cognitive impairment in AIDS patients. AIDS, 10: 493-499.

90. Martinez, A.J., M. Sell, T. Mitrovics, G. Stoltenburg-Didinger, J.R. Inglesias-Rozas, M.A. Giraldo-Velasquez, G. Gosztonyi, V. Schneider and J. Navarro-Cervos, 1995. The neuropathology and epidemiology of AIDS. A Berlin experience. A review of 200 cases. Patholog. Res. Practice, 191: 427-443.
91. Davies, J., I.P. Everall, S. Weich, L.R. Sharer, E.S. Cho, J.E. Bell, C. Majteny, F. Gray, F. Scaravilli, and P.L. Lantos, 1998. HIV-associated brain pathology: a comparative international study. Neuropathol. Appl. Neurobiol., 24: 118-124.

92. Kleihues, P., S.L. Leib, C. Strittmatter, O.D. Wiestler and W. Lang, 1991. HIV encephalopathy: Incidence, definition and pathogenesis. Results of a Swiss collaborative study. Acta Neurolog. Japan, 41: 197-205.

93. Rempel, H.C. and L. Pulliam, 2005. HIV-1 Tat inhibits neprilysin and elevates amyloid beta. AIDS, 19: 127-135.

94. Rowland-Jones, S.L., 2003. AIDS pathogenesis: what have two decades of HIV research taught us? Nature Rev. Immunol., 3: 343-348.

95. Forton, D.M., J.M. Allsop, J. Main, G.R. Foster, H.C. Thomas and S.D. Taylor-Robinson, 2001. Evidence for a cerebral effect of the hepatitis C virus. Lancet, 358:38-39.

96. Laskus, T., M. Radkowski, D.M. Adair, J. Wilkinson, A.C. Scheck and J. Rakela, 2005. Emerging evidence of hepatitis $\mathrm{C}$ virus neuroinvasion. AIDS, 19 (Suppl. 3): S140-S144.

97. Maggi, F., C. Fornai, M.L. Vatteroni, G. Siciliano, F. Menichetti, C. Tascini, S. Specter, M. Pistello, and M. Bendinelli, 2001. Low prevalence of TT virus in the cerebrospinal fluid of viremic patients with central nervous system disorders. J. Med. Virol., 65: 418-422. 